\title{
Workplace social capital and mental health: a cross-sectional study among Iranian workers
}

\author{
Mojgan Firouzbakht ${ }^{1}$, Aram Tirgar ${ }^{1 *}$, Tuula Oksanen ${ }^{2}$, Ichiro Kawachi ${ }^{3}$, Karimollah Hajian-Tilaki $^{4}$, Maryam Nikpour ${ }^{1}$, \\ Susan Mouodi ${ }^{1}$ and Reza Sadeghian ${ }^{5}$
}

\begin{abstract}
Background: The psychosocial environment of the workplace has received less attention in terms of occupational health. Trust, social network and social cohesion at the workplace (that is, factors related to social capital) may have effects on employee health. Thus, the objective of this study was to examine the association between workplace social capital and mental health among Iranian workers.

Methods: In this cross-sectional study, data were obtained from 5 factories in Babol, Northern Iran, in 2016, where 280 workers responded to a survey on social capital at work and psychosocial distress.

Results: Approximately $23.6 \%$ of the workers had psychological distress, and $23.4 \%$ had low social capital in the workplace. There was a significant relationship between mental health and individual workplace social capital $(p=0$. 025) and aggregated workplace social capital $(p=0.027)$. After controlling for each individual's characteristics, the prevalence ratio of psychological distress was 2.11 (95\% Cl: 1.43-3.17) times higher among workers with low individual social capital, and low aggregated workplace social capital was associated with 2.64 (95\% Cl: 1.28-5.45) times higher odds of psychological distress.

Conclusion: Higher social capital is associated with a reduced risk of psychological distress. The promotion of social capital can be considered as a means to increase workplace mental health among workers.
\end{abstract}

Keywords: Social capital, Workplace, Mental health, Workers, Iranian, Psychological distress

\section{Background}

In developing countries, a wide range of diseases (including physical and mental diseases) are associated with social factors [1]. The WHO has further stated that social capital is one of the factors affecting health that could be a missing link in health-related studies [2], be protective of mental health and reduce stress [3]. Social capital is defined as the resources accessed through social networks $[4,5]$. These resources include the exchange of tangible support (e.g., cash loans, labor in kind, etc.) between network members, as well as intangible resources such as emotional support or the diffusion of information. Social capital is hypothesized to

\footnotetext{
* Correspondence: a.tirgar@mubabol.ac.ir

${ }^{1}$ Social Determinants of Health Research Center, Health Research Institute,

Babol University of Medical Sciences, Babol, Iran

Full list of author information is available at the end of the article
}

promote health through several mechanisms including the following: (a) strengthening the individual's ability to cope with stress (the "buffering hypothesis"), (b) acting in accordance with the established norms among the individuals within a group or workforce, and (c) boosting the individuals' ability to participate in collective action to guarantee its members' benefits ("collective efficacy"). Social capital has been studied in a number of settings, including the family [6], neighborhood [7] and the workplace [8-10]. Considerable efforts have been applied in recent years on understanding the role of workplace social capital as a determinant of workers' health. The workplace is considered to be a major social "context" to which working age adults devote a large fraction of their waking time [11]. Employment status as well as specific conditions in the workplace, such as occupational stress, working hours and job insecurity, has been shown to

(c) The Author(s). 2018 Open Access This article is distributed under the terms of the Creative Commons Attribution 4.0 International License (http://creativecommons.org/licenses/by/4.0/), which permits unrestricted use, distribution, and reproduction in any medium, provided you give appropriate credit to the original author(s) and the source, provide a link to the Creative Commons license, and indicate if changes were made. The Creative Commons Public Domain Dedication waiver (http://creativecommons.org/publicdomain/zero/1.0/) applies to the data made available in this article, unless otherwise stated. 
have a large influence on employee mental health [12]. In the past few decades, the psychosocial environment of the workplace as a determinant of employee health has received much attention. According to some investigations, characteristics of workplace social capital, namely, trust, social networks and social cohesion, probably influence employees' health $[8,13]$. Organizations with high social capital have more satisfied, healthier, happier and more productive employees than those with low social capital [14]. A cohort study among 48,592 workers in the public sector in Finland showed that low social capital is related to a $20-50 \%$ increased risk for onset of depression [14]. A study on 2000 industrial workers the USA showed that low social capital is related to reduced smoking and job stress [3]. However, there is a lack of evidence for the effect of social capital at work on mental health in developing countries [10].

Therefore, a cross-sectional study was conducted to evaluate the workplace social capital in five factories in Iran. Both individual and workplace level social capital and their association with employee mental health were assessed using a psychological distress questionnaire.

\section{Methods}

\section{Study population and design}

A cross-sectional study was performed at five factories (26 units nested within factories) in the city of Babol on the coast of the Caspian Sea in Northern Iran in 2016. The factories were selected using convenience sampling from a variety of industries: the metal $(n=250)$, cellulosic products $(n=200)$, foodstuffs $(n=80)$, and electrical and home appliance $(n=150)$ industries. The sample size in the study was estimated to detect the effect size of 0.25 with a $95 \%$ confidence interval and $80 \%$ power of 240 subjects with estimated $20 \%$ dropped samples of 285 employees. Thus, questionnaires were administered to 350 randomly selected workers who met the inclusion criteria, and 280 workers responded (response rate of $81 \%$ ).

The inclusion criteria included at least 6 months work experience in the factories. Employees with a history of mental illness at the onset of work, or that had a stressful event (divorce, marriage, death of close relative, etc.) within the last 6 months were excluded. Survey data on demographic characteristics, social capital at the workplace and mental health were obtained.

\section{Mental health}

Mental health was assessed using the General Health Questionnaire, GHQ-12. This is a brief, simple and valid tool for measuring psychological distress [15]. This questionnaire consists of 12 questions rated on a four-point Likert scale (less than usual, not more than usual, rather more than usual, or much more than usual). The first two options were given a 0 score and the other two options a 1 score; the range of total scores in this questionnaire is $0-12$. The cut-off point of 3.5 was used in this questionnaire and higher scores indicated mental health problems [16]. This questionnaire has been translated to different languages, including Persian [17], and has been validated in several studies in Iran [16].

\section{Workplace social capital}

Social capital in the workplace was assessed using an 8 -item questionnaire designed and validated in the Finnish Public Sector study by Kouvonen et al. [9]. Reliability of the questionnaire has been confirmed in several studies with a Cronbach's alpha coefficient of 0.88 [18]. The responses were given on a 5-point Likert scale: from 1 (totally disagree) to 5 (totally agree); the total scores ranging between 8 and 40 and an average score [23] was used for dichotomizing low and high social capital, using the mean score of cut off values. A higher score indicated a high level of social capital. Social capital was assessed at the individual and workplace levels using this tool. The aggregate workplace social capital was calculated using the scores of at least three coworkers in the same work unit [9].

\section{Data were obtained from $\mathbf{2 6}$ units in the $\mathbf{5}$ factories}

The questionnaire was translated using the International Quality Of Life (IQOLA) proposed protocol with backward and forward translations techniques [19].

After obtaining permission from the authors, it was translated into Persian by two independent translators. After examining the semantic equivalents, the difficulty and clarity of the two translations were mixed and the Persian questionnaire was returned to two other translators to restore the original context (backward and forward translation).

The last stage was also repeated in this process. Then, the questionnaire was sent to the authors for approval. The validity was evaluated in 30 eligible workers in a pilot study.

The internal consistency was examined using Cronbach's alpha. In addition, the test retest consistency was examined with a two-week interval, and the intra-class correlation (ICC) was estimated. The acceptable minimum correlation coefficient was $70 \%$. The results of the tests were: test-retest correlation, 0.68 ; Cronbach's alpha, 0.78 and ICC, 0.76 (95\% CI 0.38-0.85).

\section{Covariates}

The demographic characteristics included the social and individual characteristics (age, sex, marital status (single/ married), education level (high school/university), economic status (self-reported poor, moderate or good), work experience (years), hours of work per month, shift 
work (yes/no), and the number of coworkers in their own work unit.

Self-rated health was used to measure health. The respondents completed an assessment of their current health using a five-point Likert scale $(1=$ very good, $2=$ good, $3=$ average, $4=$ poor and $5=$ very poor). Self-rated health is one of the most widely used measures of health status [20], which is shown to be related to a number of important medical endpoints $[21,22]$ and sensitive to changes in health status [23]. In this study, the scale of self-rated health was dichotomized to "good" (responses 1-2) and "poor" (responses 3-5).

\section{Statistical analysis}

The association between baseline characteristics and workplace social capital and mental health was analyzed using descriptive statistics. The log binomial regression was used to estimate the adjusted prevalence ratio (PR) and its 95\% confidence interval for individual social capital data. For estimation of the aggregated workplace social capital and poor mental health, a generalized estimating equation (GEE) was used with an exchangeable correlation matrix and binary logistic model, for adjusted clustering of workers within work units. Missing data $(3-10 \%)$ are presented in our data; to handle missing values in the calculation of the total score, the missing data were individually replaced by the mean value of scores. All statistical analysis was performed using the SPSS statistical software version 21 (Chicago,Illinois: SPSS Inc.) with a significance level of less than 0.05 , and all tests were performed for two sides.

\section{Results}

The mean age (SD) and work experience of the workers were 32.2 (6.7) and 7.4 (5.3) years, respectively, and the mean monthly working hours was 230.98 (60.6) (Table 1). The mean (SD) score of individual level social capital was 31 (5.9) and $23.6 \%$ of the workers have psychological distress. Table 2 shows the associations of the baseline covariates and social capital and mental health. For example, economic status was associated with mental health $(P=0.004)$; education was associated with individual workplace social capital $(p=$ $0.012)$ and aggregate workplace social capital $(p=0.01)$. Self-reported health was associated with individual level workplace social capital $(p=0.001$ ((Table 2).

A statistically significant relationship was found between mental health and individual level social capital. The PR low versus high workplace social capital on low mental health was 2.11 (95\% CI: 1.43-3.17) when adjusted for all baseline covariates. Similarly, low aggregated workplace social capital was associated with poor mental health after adjusting for clusters: $O R=2.64$ (95\% CI: 1.28-5.45) (Table 3).
Table 1 Demographic characteristics of Iranian workers

\begin{tabular}{lll}
\hline Demographic Characteristic & N(\%)/Mean \pm SD ( Median) \\
\hline Age (year) & & $32.21 \pm 6.71(31)$ \\
Work experience(year) & & $7.46 \pm 5.27(7)$ \\
Time of working (hours/month) & $230.98 \pm 60.6(230)$ \\
Gender & Women & $78(29.3)$ \\
& Men & $188(70.7)$ \\
Marital Status & Single & $57(23.2)$ \\
& Married & $188(76.8)$ \\
Education & High school & $76(28.1)$ \\
& University & $194(71.9)$ \\
Shift work & Yes & $166(64.09)$ \\
Residential status & No & $93(35.9)$ \\
& City & $143(58.3)$ \\
Economic Status & Village & $102(41.7)$ \\
& Poor & $89(33.3)$ \\
& Moderate & $144(53.9)$ \\
Self- health rated & Good & $34(12.7)$ \\
& Poor & $116(43.9)$ \\
& good & $148(56.1)$ \\
\hline
\end{tabular}

\section{Discussion}

This study aimed to evaluate the associations between workplace social capital and mental health among Iranian workers. It had been found that both low individual and aggregated workplace social capital were associated with poor mental health. Several studies have shown the relationship between mental health and social capital [11, 14, $24,25]$. The results of the present study are in line with those of Patussi [24] in Brazil; they showed that an increase in social capital in female workers was associated with an improvement in mental health and the promotion of healthy behaviors.

Social capital and mental health may be connected by several potential mechanisms including the individuals' ability to address stress [3,25], and occupational stress $[26,27]$ increases if there is higher social capital in the workplace. Second, the support of fellow workers is beneficial to the employees [28] because social support is a source of health promotion and provision [29]. Third, in an integrated workplace, health behaviors and collective actions can be more efficient and can reduce occupational injuries in the workplace [28, 29]. Fourth, healthy behaviors and collective action are believed to be more effective in integrated workplaces and reduce job-related injuries in the workplace $[28,29]$. Moreover, health related information is probably circulated more rapidly [30] in work environments with higher social capital [28]. It was shown by some investigators that the psychological distress of the employees is impeded by the buffering effects of their workplace social capital [31]. 
Table 2 Relationship between demographic characteristics and mental health, workplace social capital (individual and aggregation) of worker

\begin{tabular}{|c|c|c|c|c|c|c|c|c|c|c|}
\hline \multicolumn{2}{|c|}{ Demographic Characteristic } & \multirow{2}{*}{\multicolumn{2}{|c|}{ Mental Health }} & \multirow[t]{3}{*}{$P$} & \multicolumn{6}{|c|}{ Workplace social capital } \\
\hline & & & & & \multicolumn{2}{|l|}{ Individual } & \multirow[t]{2}{*}{$P$} & \multicolumn{2}{|l|}{ Aggregated } & \multirow[t]{2}{*}{$P$} \\
\hline & & Yes N(\%) & No N(\%) & & High N(\%) & Low N(\%) & & High N(\%) & Low N(\%) & \\
\hline \multirow[t]{2}{*}{ Gender } & Women & $53(27.2)$ & 24(20.9) & NS & $58(24.6)$ & 13(21.1) & NS & $44(24.2)$ & 14(14.5) & NS \\
\hline & Men & $125(72.8)$ & 63(79.1) & & $152(75.4)$ & $38(78.9)$ & & 133(57.8) & $63(58.5)$ & \\
\hline \multirow[t]{2}{*}{ Marital Status } & Single & $37(17.1)$ & $20(14.7)$ & NS & $39(14.7)$ & $21(28.9)$ & NS & $17(11.3)$ & $39(17.8)$ & NS \\
\hline & Married & $131(82.9)$ & $58(85.3)$ & & 178(85.3) & $37(71.1)$ & & 65(88.7) & $144(82.2)$ & \\
\hline \multirow[t]{2}{*}{ Education } & High school & $51(29.1)$ & $25(35.8)$ & NS & $70(32.5)$ & $11(21.1)$ & NS & $60(36.8)$ & 19(31.1) & $0.01^{*}$ \\
\hline & University & 132(70.8) & $62(62.2)$ & & $145(67.3)$ & $47(78.9)$ & & $160(63.2)$ & $31[6]$ & \\
\hline \multirow[t]{2}{*}{ Shift work } & Yes & $112(65.8)$ & $54(69.7)$ & NS & 128(70.3) & $34(70.3)$ & NS & $101(63.5)$ & $47(75.8)$ & NS \\
\hline & No & 63(34.1) & $30(30.3)$ & & $81(29.7)$ & 19(29.7) & & $58(36.4)$ & 15(23.2) & \\
\hline \multirow[t]{2}{*}{ Residential status } & City & 103(61.7) & $40(50.7)$ & NS & $26(47.4)$ & $28(52.6)$ & NS & 120(69.6) & $34(44.1)$ & $0.001^{*}$ \\
\hline & Village & $67(83.3)$ & $42(49.3)$ & & $81(39.5)$ & $123(60.5)$ & & $57(30.4)$ & $41(55.9)$ & \\
\hline \multirow[t]{3}{*}{ Economic Status } & Poor & $51(27.6)$ & $38(4.5)$ & $0.008^{*}$ & $22(43.6)$ & $15(4.5)$ & NS & $64(62.1)$ & $28(27.1)$ & NS \\
\hline & Moderate & 107(63.5) & $37(86.4)$ & & $23(46.2)$ & 175(86.4) & & 106(58.8) & $37(50)$ & \\
\hline & Good & $21(8.8)$ & 13(7.6) & & 10(10.3) & $25(7.6)$ & & $16(6.1)$ & $14(12.9)$ & \\
\hline \multirow[t]{2}{*}{ Self- health rated } & Poor & 77(38.4) & 39(58.9) & $0^{*}$ & 83(41.9) & $32(50)$ & $0.001^{*}$ & $73(40.5)$ & 27(34.6) & NS \\
\hline & Good & 108(16.7) & $38(41.2)$ & & $123(48.1)$ & $32(50)$ & & 107(59.4) & $51(65.3)$ & \\
\hline
\end{tabular}

*Significance level $=p<0.05, \mathrm{NS}=$ No significance

The results of this study showed that $23.6 \%$ of workers had psychosocial distress. These results are consistent with reports by other researchers [32-34]. In the current study, economic status was associated with mental health. The finding corresponds with previous studies showing that financial stress (low income or poverty) and economic insecurity (unemployment or temporary jobs and debts) increase the risk of mental distress [35]. Moreover, in health inequality studies, the social environment is a social factor that can improve health. Social capital may buffer the inequality of health [36]. People who have higher social capital and higher social support have more access to material (money, food and health centers) and nonmaterial (information and health-related norms) resources [37].

Several studies indicated that social capital at the individual level can be determined by various socio-economic factors such as educational level, economic status and employment status [26, 38-40]. In other words, social capital is most likely to be determined by the social context in which an individual lives, such as family, neighborhood and work environment [41]. Conceptually, social capital reflects the social structure of relationships and is a collective feature [42]. In this study, workplace social capital was associated with the level of education and number of coworkers, which is similar to the results of Oksanen [14], who reported a significant correlation between the characteristics of the workplace (number of coworkers, hours of work absences and manual jobs) and workplace social capital.

The results of this study need to be interpreted in light of the following strengths and limitations. This is the first study on workplace social capital and health in the Iranian workforce. Although the sample size is small, the response rate was sufficient and workplace social capital was assessed with a standardized workplace social capital questionnaire.

Workplace social capital may be affected by social capital outside workplaces, and vice versa. However, social

Table 3 Crude and adjusted PR (CI 95\%) and OR (CI 95\%) association of individual and aggregated workplace social capital and poor mental health

\begin{tabular}{llll}
\hline & & Unadjusted Model & Adjusted model \\
\hline Individual workplace social capital(PR) & high & $1(-)$ & $1(-)$ \\
& low & $1.68(1.05-2.69)$ & $2.11(1.41-3.17)$ \\
Work place social capital(OR) Aggregated & High & $1(-)$ & $1(-)$ \\
& low & $2.43(1.27-4.67)$ & $2.64(1.28-5.45)$ \\
\hline
\end{tabular}


capital outside the workplace setting was not assessed. This study is cross-sectional, and thus, the temporal sequence of low workplace social capital and poor mental health remained unsolved. Thus, causal interpretation of its apparent association must be done cautiously.

\section{Conclusion}

The result of this study shows that high social capital in the workplace is associated with a better mental health status of workers. Therefore, the promotion of social capital can be introduced as one of the strategies to improve mental health in the workplace. Additional studies on social capital and mental health in developing countries are needed.

\section{Abbreviations}

Cl: Confidence interval; GEE: Generalized estimating equation; GHQ: General health questionnaire; ICC: Intra-class correlation; IQOLA: International quality of life assessment; OR: Odds ratio; PR: Prevalence rate; WHO: World Health Organization

\section{Acknowledgements}

The authors thank the all workers that participated in this project.

\section{Availability of data and materials}

The datasets analyzed during the current study are available from the corresponding author on reasonable request.

\section{Authors' contributions}

MF and AT: study conception and design. MN and RS: Acquisition of data. KHT and IK: Analysis and interpretation of data. MF, AT, TO and Ik: Drafting of manuscript. MF, AT, SM, TO and Ik: Critical revision. All authors read and approved the final manuscript.

\section{Ethics approval and consent to participate}

The study was approved by the Ethics Committee of Babol University of Medical Sciences, Babol, Iran (Ethics Code: MUBABOL, HRI.REC.1395.84). All participants were informed about the study aims and procedures. Moreover, they were ensured that participation was voluntary. The confidentiality of participants' information was guaranteed. The participants signed a consent form which was attached to the study instrument.

\section{Consent for publication}

Not applicable.

\section{Competing interests}

The authors declare that they have no competing interests.

\section{Publisher's Note}

Springer Nature remains neutral with regard to jurisdictional claims in published maps and institutional affiliations.

\section{Author details}

${ }^{1}$ Social Determinants of Health Research Center, Health Research Institute, Babol University of Medical Sciences, Babol, Iran. ${ }^{2}$ Finnish Institute of Occupational Health, Turku, Finland. ${ }^{3}$ Department of Social and Behavioral Sciences, Harvard T.H. Chan School of Public Health, Boston, MA, USA. ${ }^{4}$ Department of Biostatistics and Epidemiology, Babol University of Medical Science, Babol, Iran. ${ }^{5}$ Babol, Iran.
Received: 27 May 2018 Accepted: 1 June 2018

Published online: 26 June 2018

\section{Refrences}

1. Hughes LW. A correlational study of the relationship between sense of humor and positive psychological capacities. Econ Bus J Inq Perspect. 2008: 1(1):46-55.

2. Solar $\mathrm{O}$, Irwin A. A conceptual framework for action on the social determinants of health. 2007

3. Sapp AL, Kawachi I, Sorensen G, LaMontagne AD, Subramanian S. Does workplace social capital buffer the effects of job stress? A cross-sectional, multilevel analysis of cigarette smoking among US manufacturing workers. Journal of occupational and environmental medicine/American College of. Occup Environ Med. 2010;52(7):740.

4. Kawachi I, Subramanian SV, Social Capital KD. Health. In: Kawachi I, Subramanian SV, Kim D, editors. Social Capital and Health. New York, NY: Springer New York; 2008. p. 1-26.

5. Bourdieu P. Distinction: A social critique of the judgement of taste. Cambridge: Harvard University Press; 1984.

6. Alvarez EC, Kawachi I, Romani JR. Family social capital and health - a systematic review and redirection. Sociol Health IIIn. 2017;39(1):5-29.

7. Ruef M, Kwon S-W. Neighborhood Associations and Social Capital. Soc Forces. 2016;95(1):159-90.

8. Read EA. Workplace social capital in nursing: an evolutionary concept analysis. J Adv Nurs. 2014;70(5):997-1007.

9. Oksanen T, Kouvonen A, Kivimäki M, Pentti J, Virtanen M, Linna A, et al. Social capital at work as a predictor of employee health: multilevel evidence from work units in Finland. Soc Sci Med. 2008;66(3):637-49.

10. Kouvonen A, Kivimäki M, Vahtera J, Oksanen T, Elovainio M, Cox T, et al. Psychometric evaluation of a short measure of social capital at work. BMC Public Health. 2006;6(1):251.

11. Kawachi I, Kennedy BP, Glass R. Social capital and self-rated health: a contextual analysis. Am J Public Health. 1999:89(8):1187-93.

12. Harnois G, Gabriel P, Organization WH. Mental health and work: impact, issues and good practices. 2000.

13. Kawachi I. Social capital and community effects on population and individual health. Ann N Y Acad Sci. 1999:896:120-30.

14. Oksanen T, Kouvonen A, Vahtera J, Virtanen M, Kivimaki M. Prospective study of workplace social capital and depression: are vertical and horizontal components equally important? J Epidemiol Community Health. 2010;64(8): 684-9.

15. Montazeri A, Harirchi AM, Shariati M, Garmaroudi G, Ebadi M, Fateh A. The 12-item General Health Questionnaire (GHQ-12): translation and validation study of the Iranian version. Health Qual Life Outcomes. 2003;1:66.

16. Ebadi M, HARIR CA, Shariati M, GARMAROUDI GR, Fateh A, Montazeri A. Translation, reliability and validity of the 12-item general health questionnaire among young people in Iran. 2002.

17. Tagharrobi Z, Sharifi K, Sooky Z. Psychometric Analysis Of Persian Ghq-12 With C-Ghq Scoring Style. PCNM. 2015;4(2):66-80.

18. Idrovo AJ, Camacho-Avila A, García-Rivas J, Juárez-García A. Social capital at work: psychometric analysis of a short scale in Spanish among Mexican health workers. Rev Bras Epidemiol. 2012;15(3):536-47.

19. Slater $\mathrm{CH}$, Bick D. Quality of life research: an international journal of quality of life aspects of treatment, care and rehabilitation. JAMA. 1994; 271(17):1377.

20. Krause NM, Jay GM. What Do Global Self-Rated Health Items Measure? Med Care. 1994:32(9):930-42.

21. Kivimäki M, Head J, Ferrie JE, Shipley MJ, Vahtera J, Marmot MG. Sickness absence as a global measure of health: evidence from mortality in the Whitehall II prospective cohort study. Bmj. 2003;327(7411):364.

22. Idler EL, Benyamini Y. Self-rated health and mortality: a review of twentyseven community studies. J Health Soc Behav. 1997:21-37.

23. Bailis DS, Segall A, Chipperfield JG. Two views of self-rated general health status. Soc Sci Med. 2003:56(2):203-17.

24. Pattussi MP, Olinto MTA, Canuto $R$, da Silva Garcez A, Paniz VMV, Kawachi I. Workplace social capital, mental health and health behaviors among Brazilian female workers. Soc Psychiatry Psychiatr Epidemiol. 2016:51(9):1321-30.

25. Kouvonen A, Oksanen T, Vahtera J, Väänänen A, De Vogli R, Elovainio M, et al. Work-place social capital and smoking cessation: the Finnish Public Sector Study. Addiction. 2008;103(11):1857-65. 
26. Lindström M, Merlo J, Östergren P-O. Individual and neighbourhood determinants of social participation and social capital: a multilevel analysis of the city of Malmö, Sweden. Soc Sci Med. 2002;54(12):1779-91.

27. Chen D-R, Lin Y-Y, Chung K-P. Career stress and female managers' health in Taiwan's hospitals: A multilevel model approach. Health Care Manage Rev. 2008:33(1):40-50

28. Suzuki E, Takao S, Subramanian S, Komatsu H, Doi H, Kawachi I. Does low workplace social capital have detrimental effect on workers' health? Soc Sci Med. 2010;70(9):1367-72.

29. Hill JL, Wilson K, Harden S, Almeida F, Linnan L, Estabrooks PA. Does worksite social capital enhance retention into a worksite weight-loss programme? Obesity Science \& Practice. 2016;2(1):69-74.

30. Kawachi I, Berkman LF. Social ties and mental health. J Urban Health. 2001; 78(3):458-67.

31. Inoue A, Kawakami N, Eguchi $H$, Tsutsumi A. Buffering effect of workplace social capital on the association of job insecurity with psychological distress in Japanese employees: a cross-sectional study. J Occup Health. 2016;58(5):460-9.

32. Gao J, Weaver SR, Dai J, Jia Y, Liu X, Jin K, et al. Workplace social capital and mental health among Chinese employees: a multi-level, cross-sectional study. PloS one. 2014;9(1):e85005.

33. Koohpaie A R, Khandan M. Assessment of Mental Health Level among Workers of Industries in Qom Province, 2014-2015, Iran. Qom Univ Med Sci J. 2015:9(8):66-74.

34. Halvani G, Morowatisharifabad M, Baghianimoghadam M. Determining the general health status of workers of Kuushk mine. koomesh. 2007:8(4):261-68.

35. Insel TR. Assessing the economic costs of serious mental illness. Am J Psychiatry. 2008;165(6):663-5.

36. Uphoff EP, Pickett KE, Cabieses B, Small N, Wright J. A systematic review of the relationships between social capital and socioeconomic inequalities in health: a contribution to understanding the psychosocial pathway of health inequalities. Int J Equity Health. 2013;12(1):54.

37. Berkman LF, Glass T. Social integration, social networks, social support, and health. Soc Epidemiol. 2000;1:137-73.

38. Putnam RD. Bowling alone: The collapse and revival of American community.NewYork: Simon and Schuster; 2001.

39. Baum FE, Bush RA, Modra CC, Murray CJ, Cox EM, Alexander KM, et al. Epidemiology of participation: an Australian community study. J Epidemiol Community Health. 2000;54(6):414-23.

40. Kaasa A, Parts E. Individual-level determinants of social capital in Europe differences between country groups. Acta Sociol. 2008;51(2):145-68

41. Kawachi I, Berkman L. Social cohesion, social capital, and health. Soc Epidemiol. 2000:174-90,

42. Verhaeghe P-P, Pattyn E, Bracke P, Verhaeghe M, Van De Putte B. The association between network social capital and self-rated health: pouring old wine in new bottles? Health Place. 2012;18(2):358-65.

\section{Ready to submit your research? Choose BMC and benefit from:}

- fast, convenient online submission

- thorough peer review by experienced researchers in your field

- rapid publication on acceptance

- support for research data, including large and complex data types

- gold Open Access which fosters wider collaboration and increased citations

- maximum visibility for your research: over $100 \mathrm{M}$ website views per year

At BMC, research is always in progress.

Learn more biomedcentral.com/submissions 